(Aphaenogaster fulva) but usually take it at large.

Scopaeus brevipennis Casey (in litt.). This is the species recorded in the pre. vious paper, without a name. It occurs with Aphaenogaster fulva.

Oxytelus placusinus Lec., and $O$. suspectus Casey were taken with Formica subsericea. They probably make galleries of their own in the ant-hill rather than dwell in the run ways of the ants.

Atomaria mesomela Hbst.. "or one of the other 4-maculate species" (Brendel). This occurs at Iowa City with an Aphaenogaster, the identity of which cannot be determined with the limited material in hand. Several specimens were taken from one nest. This is probably not the customary habit of this species.

\title{
TWO CAVE BEETLES NOT BEFORE RECORDED.
}

BY H. GARMAN, LEXINGTON; KY.

Two small beetles have proved so constantly present in small caves in the vicinity of Lexington that it seems worth while to place them on record as cave insects. Both have pretty well developed eyes and may therefore live at times in ordinary situations, but they are perfectly at home in the deepest parts of caves and are at times very abundant there. In all my collecting in ordinary situations I have not seen either species out-of-doors, and am disposed to consider them true cave dwellers.

Choleva alsiosa, Horn. This is a small black beetle (one of the Silphidae) about $4.5 \mathrm{~mm}$. in length, described in 1885 by Dr. Horn from the Yukon River, Alaska. Is it possible that the low temperature prevailing in the caves has enabled this insect to persist here since glacial times? I have several hundred specimens, male and female, all taken in caves beyond the penetration of light.
Calodera cavicola, n. s. A small, reddish brown insect with very short wing covers and a slender elongated body. Head generally darker than the body, sometimes nearly black in alcoholic specimens. The middle of the abdominal somites also darker than elsewhere giving this division of the body an annulated appearance. Specimens taken from the caves and kept alive seem to me to become gradually darker in general color. It is one of the Staphilinidae.

Length 4.5-6.0 $\mathrm{mm}$. Greatest width about $1.0 \mathrm{~mm}$. Outline of head, seen from above, nearly circular, truncate behind, its length contained $I_{5}^{\frac{1}{6}}$ times in width, pubescent and obsoletely punctate above. Antennae when drawn back reaching nearly to posterior edge of prothorax, gradually enlarging from the base, finely pubescent, and with a ring of rather strong hairs on most of the segments. First to third segment cylindrical, the basal largest and longest of the three, the second and third nearly equal; fourth segment shortest, contracted 
at each extremity, widest at middle; segments five to ten, inclusive, similar in shape, being angular in outline and increasing in width from base to tip; eleventh segment largest, oval, truncated at base. Labrum slightly excavated medially, rounded at sides, with a number of rather strong setae arising from its surface, its length contained about $2 \frac{1}{2}$ times in its width from side to side. Mandible short, sickle-shaped distally, its tip acute, its cutting edge very finely denticulate and provided with a fringe of very fine setae. Lacinia of maxilla with an internal membranous expansion furnished near the tip with a series of rather strong, curved spines and a dense growth of pubescence. Galea tapering to tip, also with a

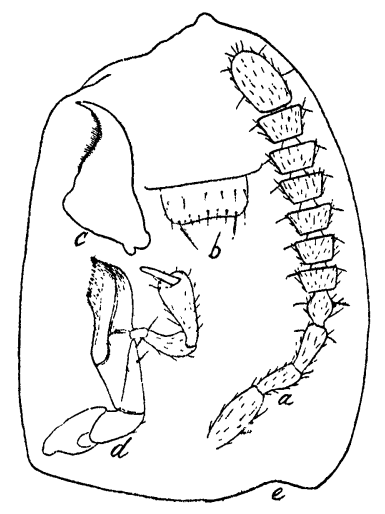

FIG. I.

Fig. I. $a$, antenna of Calodera cavicola; $b$, labrum; $c$, mandible; $d$, maxilla; $e$, outline of elytron. (From camera lucida sketehes).

dense growth of pubescence distally. Basal article of maxillary palpus very small, cylindrical; second segment gradually enlarging towards tip where it attains its greatest diameter; third segment largest, also enlarging from base to tip; distal segment small and slender, gradually tapering towards tip. Prothorax wider than head (width of head about one and a third times in width of prothorax), its length contained $I_{5}^{\frac{1}{2}}$ times in width, outline nearly circular. Elytra not quite reaching the first abdominal somite, truncate behind, with a small excavation near outer angle. Wings small and weak, not used for flight as far as observed. Sides of abdomen nearly parallel as far as the sixth somite which narrows rapidly to the seventh which is small; outline of somites seen from above nearly square; a groove along each side of the abdomen with a raised outer margin.

Color pale fulvous. Head darker, sometimes nearly black. Three anterior abdominal somites with a transverse black bar a little before the middle. Somites four and five with a larger, more obscurely outlined

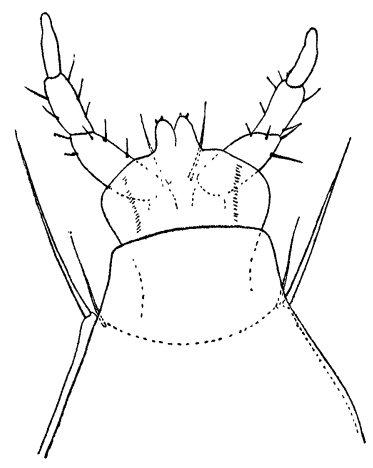

FIG. 2.

FIg. 2. Labium of C. cavicola. (From camera Jucida sketch).

dark area in place of the bar. These marks are obscure in some specimens, and show best in alcoholic specimens examined with the microscope.

The species is very common in some caves, occurring with Anophthalmus horni in the deepest parts. From the character of the ligula $\mathrm{Mr}$. E. A. Schwarz thinks it may belong to the genus Ocalea instead of Calodera. 

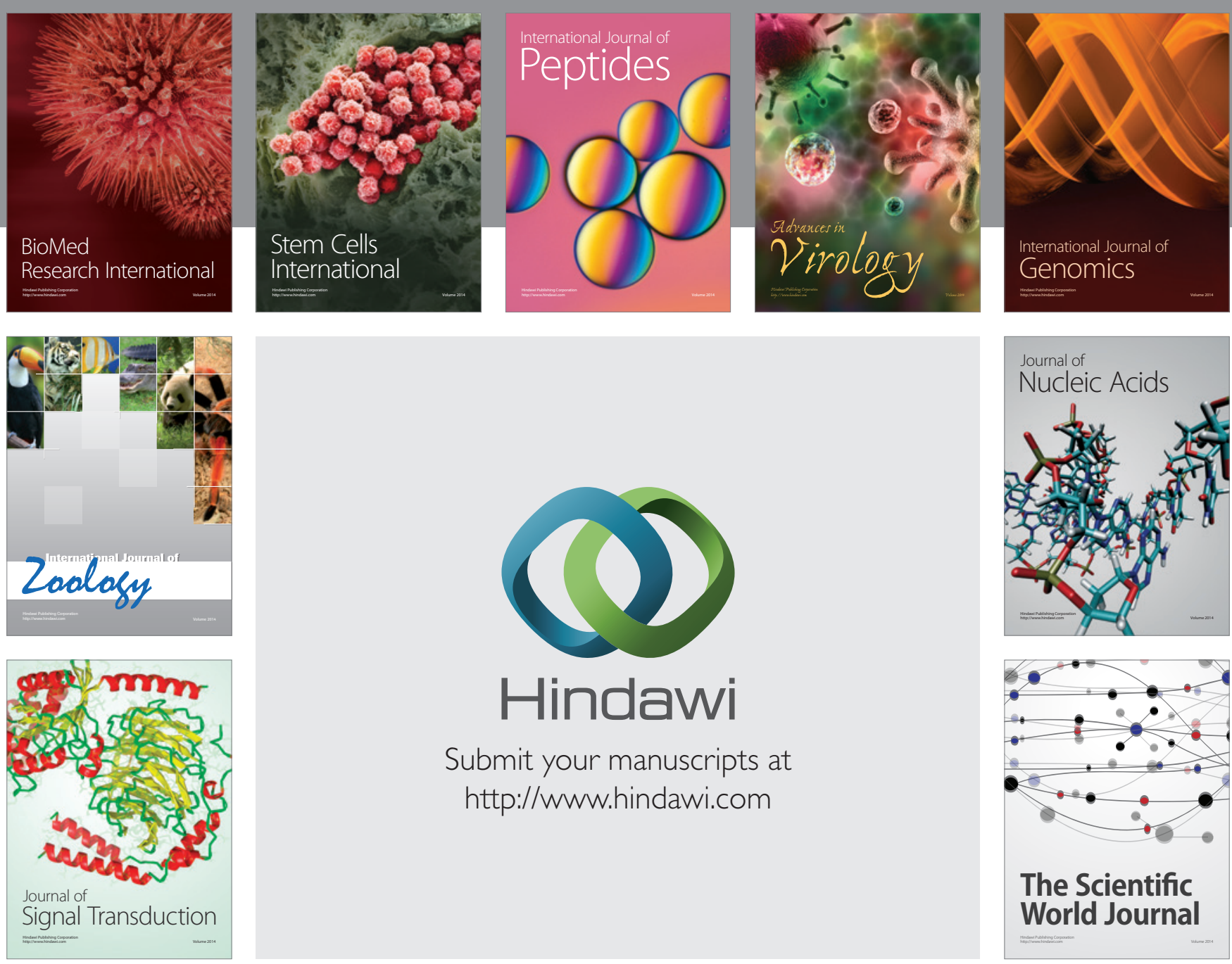

Submit your manuscripts at

http://www.hindawi.com
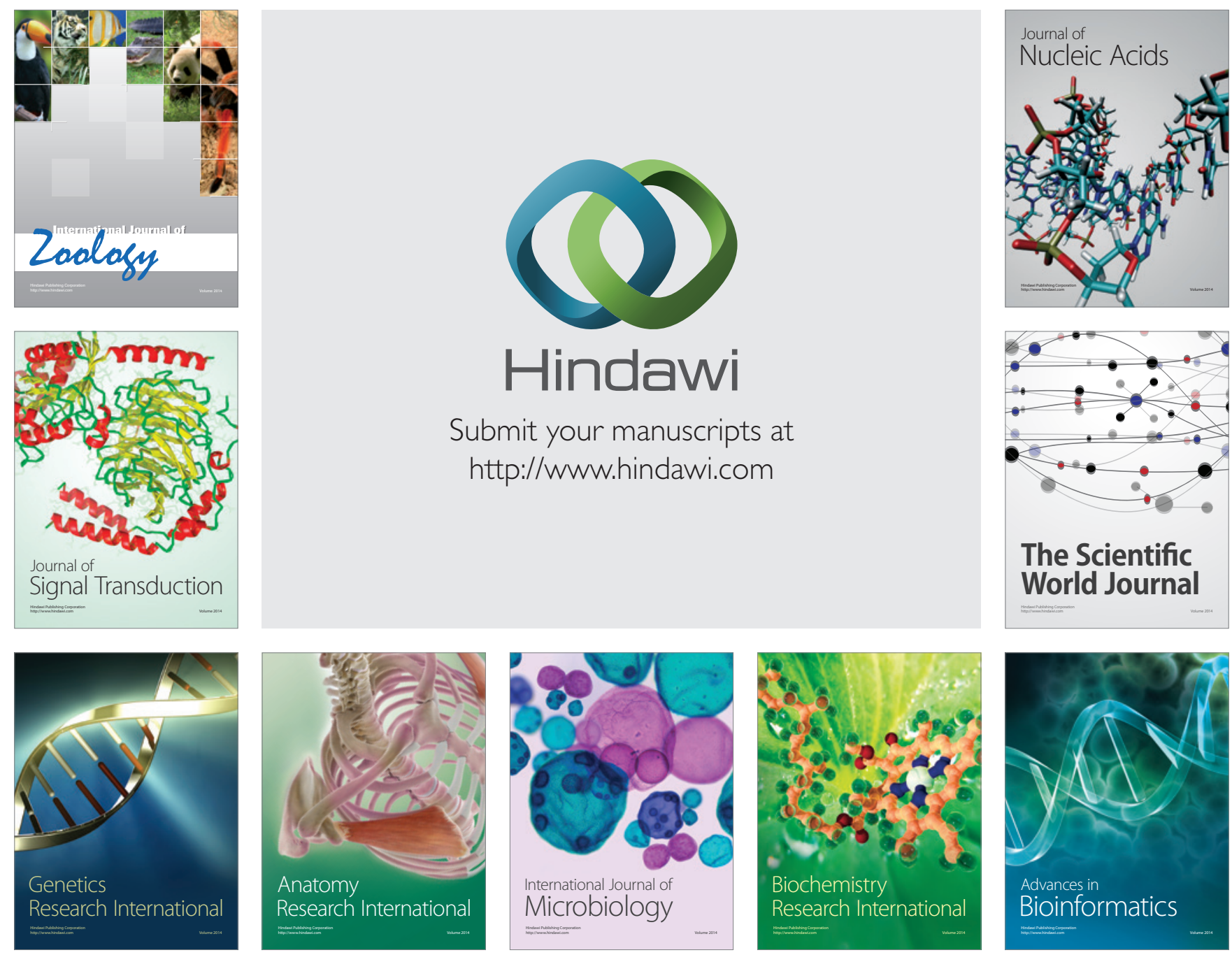

The Scientific World Journal
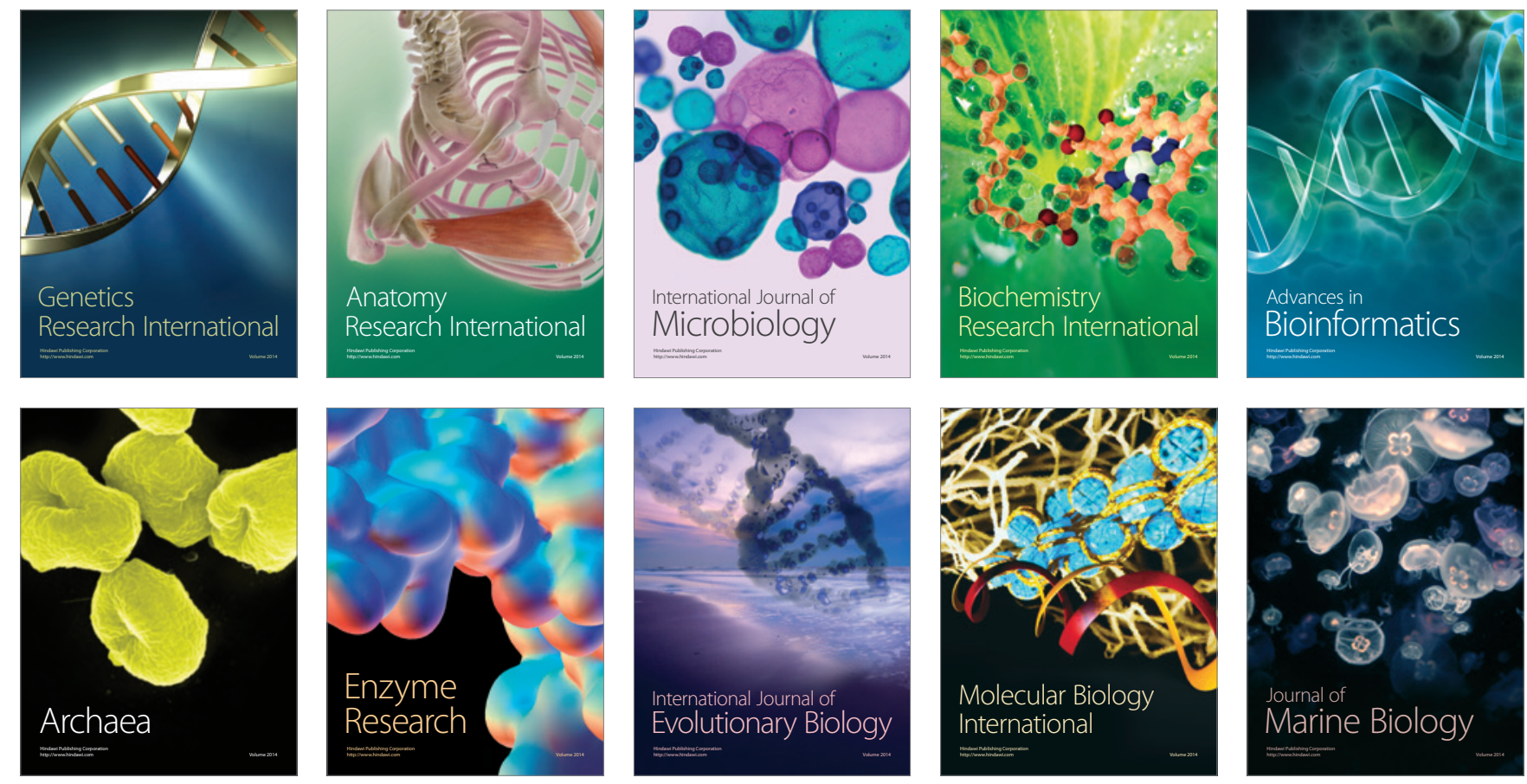